\title{
Vacancy Transfer Probabilities from K to L Shell for Low Atomic Number Elements at $5.96 \mathrm{keV}$
}

\author{
B. ERtuĞral ${ }^{a * *}$, H. Balta $\$^{b}$, A. Çelik ${ }^{a}$ And Y. Kobya ${ }^{c}$ \\ ${ }^{a}$ Faculty of Art and Sciences, Giresun University, 28100 Giresun, Turkey \\ ${ }^{b}$ Faculty of Arts and Science, Rize University, 53100 Rize, Turkey \\ ${ }^{c}$ Faculty of Art and Sciences, Artvin Çoruh University, 61080 Trabzon, Turkey
}

(Received October 17, 2009; in final form March 5, 2010)

\begin{abstract}
Vacancy transfer probabilities from $\mathrm{K}$ to $\mathrm{L}$ shell were measured using $\mathrm{I}_{\mathrm{K} \beta} / \mathrm{I}_{\mathrm{K} \alpha}$ intensity ratios for six elements in the atomic region $16 \leq Z \leq 22$. The $\mathrm{K}$ X-rays from the targets excited by $5.96 \mathrm{keV}\left(1.85 \mathrm{GBq}{ }^{55} \mathrm{Fe}\right.$ filtered annular source) incident photon were obtained using a high resolution PGT model $\mathrm{Si}(\mathrm{Li})$ detector. Theoretical values were calculated using radiative and radiationless transition rates of these elements. The measured values of $\eta_{\mathrm{KL}}$ were compared with the theoretical ones. Reasonable agreement was typically obtained between present and theoretical values.
\end{abstract}

PACS numbers: $32.80 .-\mathrm{t}, 33.20 . \mathrm{Rm}$

\section{Introduction}

When an atomic shell/subshell has been ionized, a vacancy is created in an inner shell (e.g. the K shell). This vacancy is filled up by an electron coming from some higher shell. It is excited through radiative or radiationless (Auger) transitions. K to L shell vacancy transfer probability is defined as the number of $\mathrm{L}$ shell vacancies produced in the decay of one $\mathrm{K}$ shell vacancy through radiative or Auger transitions. A knowledge of average vacancy distributions is important for the study of such processes as nuclear electron capture, internal conversion of $\gamma$-rays, photoelectric effect and generally, whenever primary vacancies produced in the shell must be distinguished from multiple ionization due to the decay of inner vacancy [1].

Recently, there were several works on L X-ray intensity ratio [2-3], K, L and M X-ray production cross-sections [4-8], Coster-Kronig transitions probabilities [9-10] and chemical effect [11] for many elements using EDXRF spectrometry.

$\mathrm{K}$ to $\mathrm{L}$ shell vacancy transfer probabilities were measured in the atomic region $37 \leq Z \leq 42$ at $5.96 \mathrm{keV}$ and $22.6 \mathrm{keV}$ energies by Puri et al. [12]. In addition to this, Puri et al. [13] evaluated the probabilities $g \eta_{\mathrm{KL}}, \eta_{\mathrm{LM}}$ and $\eta_{\mathrm{KM}}$ for elements in the atomic number region $18 \leq Z \leq$ 96. Ertuğral et al. measured $\mathrm{K}$ to $\mathrm{L}$ shell vacancy transfer probabilities using intensity ratios of $\mathrm{K}_{\alpha}$ and $L_{x}$ total $\mathrm{X}$-rays [1] and $\mathrm{I}_{\mathrm{K} \beta} / \mathrm{I}_{\mathrm{K} \alpha}$ intensity ratios [14-15] for some elements in different atomic regions. Rao et al. [16] have calculated the values of $\eta_{\mathrm{KLi}}(i=1,2,3)$ for elements in

* corresponding author; e-mail: birolertugral@hotmail.com the atomic range $20 \leq Z \leq 94$. In these calculations, the contributions due to Auger and radiative transitions were derived using the best fitted experimental data on the fluorescence yields and intensity ratios of different components of $\operatorname{KLX}(\mathrm{X}=\mathrm{L} ; \mathrm{M} ; \mathrm{N}$, etc.) Auger electrons and $\mathrm{K}$ X-rays available in those dates. Schönfeld and Janßen [17] reported K to L shell vacancy transfer probabilities for elements in the range $11 \leq Z \leq 100$ using experimental and theoretical values of $\mathrm{K}$-shell fluorescence yield, mean L-shell yield, ratios of X-ray emission probabilities, ratios of emission probabilities of Auger electrons and the vacancy transfer coefficient collected from literature.

A systematic study of $\mathrm{K}$ to $\mathrm{L}$ and $\mathrm{M}$ shells vacancy transfer probabilities measured for different elements in the atomic range $52 \leq Z \leq 92$ as a function of incident photon energy has previously been undertaken [18-22].

To the best of our knowledge there are no reports regarding the measurements of experimental vacancy transfer probabilities of $\mathrm{K}$ to $\mathrm{L}$ shell in the low atomic number elements.

In the present work, we report the measurement of vacancy transfer probabilities from $\mathrm{K}$ to $\mathrm{L}$ shell for $\mathrm{S}, \mathrm{Cl}$, $\mathrm{K}, \mathrm{Ca}$, Sc and Ti using $\mathrm{I}_{\mathrm{K} \beta} / \mathrm{I}_{\mathrm{K} \alpha}$ intensity ratios. The targets were excited with $5.96 \mathrm{keV}$ photons ${ }^{55} \mathrm{Fe}$ source. Finally, the measured values of $\eta_{\mathrm{KL}}$ were compared with all available data and the theoretical values deduced using the calculated radiative and radiationless transitions rates.

\section{Experimental procedure and calculations}

The experimental set-up, as described earlier (Apaydin et al. $[8]$ ), consists of a $\mathrm{Si}(\mathrm{Li})$ detector, a ${ }^{55} \mathrm{Fe}$ radioisotope source and a target. In this work, the studied 
elements were S, Cl, K, Ca, Sc and Ti. The purity of commercially obtained materials was better than $99 \%$. Powder samples were sieved to 400 mesh size and palletized to thickness ranging from 15 to $37 \mathrm{mg} \mathrm{cm}^{-2}$. The samples were irradiated by $5.96 \mathrm{keV}$ photons emitted by an annular $1.85 \mathrm{GBq}{ }^{55} \mathrm{Fe}$ radioactive source. The incident beam and fluorescence X-rays emitted from the target were detected and analyzed with a $\mathrm{Si}(\mathrm{Li})$ detector $\left(\mathrm{FWHM}=160 \mathrm{eV}\right.$ at $5.96 \mathrm{keV}$, active area $=13 \mathrm{~mm}^{2}$, thickness $=3 \mathrm{~mm}$ and Be window thickness $=30 \mathrm{~mm}$ ). The output from the preamplifier, with pulse pile-up rejection capability, was fed to a multi-channel analyzer interfaced with a personal computer provided with suitable software for data acquisition and peak analysis. The live time was selected to be $5000 \mathrm{~s}$ for all elements. The samples were placed at a $45^{\circ}$ angle with respect to the direct beam and fluorescent X-rays emitted in a $90^{\circ}$ direction towards the detector. Figure 1 shows a typical K $\mathrm{X}$-ray spectrum for S.

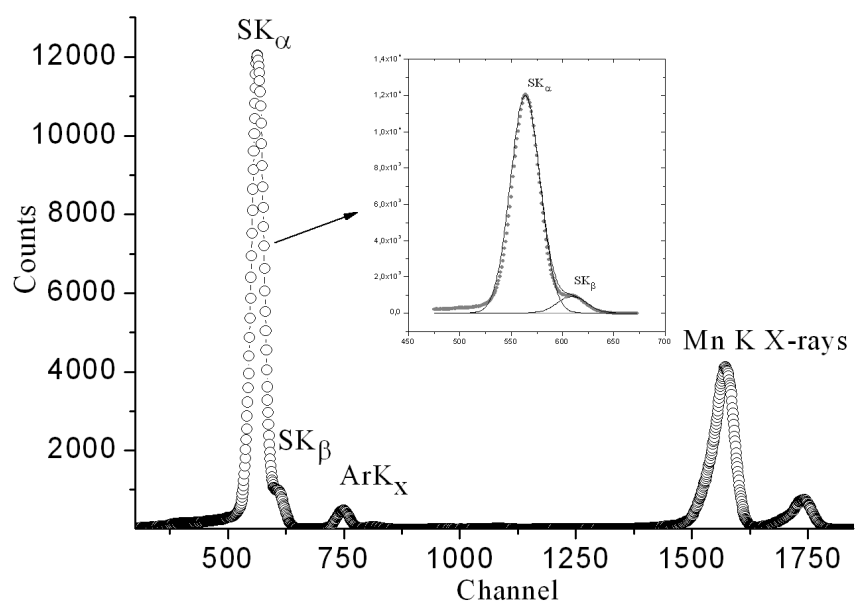

Fig. 1. Typical K X-ray spectrum for S.

The experimental $\mathrm{K}$ to $\mathrm{L}$ total vacancy transfer probabilities $\eta_{\mathrm{KL}}$ were evaluated from [17]

$$
\eta_{\mathrm{KL}}=\frac{2-\omega_{\mathrm{K}}}{1+\left(I_{\mathrm{K} \beta} / I_{\mathrm{K} \alpha}\right)},
$$

where $\omega_{\mathrm{K}}$ is the fluorescence yield of the K shell [23] and $\mathrm{I}_{\mathrm{K} \beta} / \mathrm{I}_{\mathrm{K} \alpha}$ is the intensity ratio of the $\mathrm{K}$ X-rays. We used the following equations to calculate the $\mathrm{I}_{\mathrm{K} \beta} / \mathrm{I}_{\mathrm{K} \alpha}$ intensity ratio

$$
\frac{I_{\mathrm{K} \beta}}{I_{\mathrm{K} \alpha}}=\frac{N_{\mathrm{K} \beta}}{N_{\mathrm{K} \alpha}} \frac{\beta_{\mathrm{K} \alpha}}{\beta_{\mathrm{K} \beta}} \frac{\varepsilon_{\mathrm{K} \alpha}}{\varepsilon_{\mathrm{K} \beta}},
$$

where $\mathrm{N}_{\mathrm{K} \beta}$ and $\mathrm{N}_{\mathrm{K} \alpha}$ are the net counts under the $\mathrm{K}_{\beta}$ and $\mathrm{K}_{\alpha}$ peaks, $\beta_{\mathrm{K} \beta}$ and $\beta_{\mathrm{K} \alpha}$ are the self-absorption correction factor for energies of $K_{\beta}$ and $K_{\alpha}$ peaks. The self absorption correction factor $\beta$ at the excitation energy was calculated with the following equation

$$
\beta=\frac{1-\exp \left(-\left(\mu_{\mathrm{inc}} / \sin \theta+\mu_{\mathrm{emt}} / \sin \phi\right) t\right)}{\left(\mu_{\mathrm{inc}} / \sin \theta+\mu_{\mathrm{emt}} / \sin \phi\right) t},
$$

where $\mu_{\text {inc }}$ and $\mu_{\text {emt }}$ are the total mass absorption coefficients (from XCOM [24]) of the target material at the incident photon energy and emitted average $\mathrm{K}_{\alpha}$ and $\mathrm{K}_{\beta}$ X-ray energies [25], $t$ is the thickness of the target in $\mathrm{g} \mathrm{cm}^{-2}, \theta$ and $\phi$ are the angles of incident photon and emitted X-rays with respect to the normal at the surface of the sample, respectively.

$\varepsilon_{\mathrm{K} \beta}$ and $\varepsilon_{\mathrm{K} \alpha}$ are the detector efficiencies at the energies of the $\mathrm{K}_{x} \mathrm{X}$-ray energies; which were evaluated by the equation

$$
\varepsilon_{\mathrm{Ki}}=\frac{N_{\mathrm{Ki}}}{I_{0} G \beta_{\mathrm{Ki}} m_{i} \sigma_{\mathrm{Ki}}},
$$

where $\mathrm{N}_{\mathrm{Ki}}$ and $\beta_{\mathrm{Ki}}$ have the same meaning as in Eq. (2). The term $I_{O}$ is the intensity of exciting radiation, $G$ is the geometry factor, $m_{i}$ is the mass of the element in the sample in $\mathrm{g} \mathrm{cm}^{-1}$. Absolute efficiency $\varepsilon$ of the X-ray detector was obtained by using Eq. (4). $\mathrm{K}_{\alpha}$ and $\mathrm{K}_{\beta} \mathrm{X}$-ray peak of Al, Si, P, S, K, Ca and Sc elements were collected for this measurement by using compounds of these elements at the same condition for the intensity ratio measurements. This measurement was also explained in one of our previous papers [8].

The term $\sigma_{\mathrm{Ki}}$ represents the K X-ray fluorescence cross sections and is given as

$$
\sigma_{\mathrm{Ki}}=\sigma_{\mathrm{K}}^{\mathrm{P}} \omega_{\mathrm{K}} f_{\mathrm{Ki}} \text {, }
$$

where $\sigma_{\mathrm{K}}^{\mathrm{P}}$ is the $\mathrm{K}$ shell photoionization cross section [26] and $f_{\mathrm{Ki}}$ is the fractional $\mathrm{X}$-ray emission rate [27].

Theoretical calculations were made according to a previous paper [1].

\section{Results and discussion}

The measured values of the $\mathrm{K}$ to $\mathrm{L}$ shell vacancy transfer probability, $\eta_{\mathrm{KL}}$, for 6 elements namely, S, Cl, K, Ca, $\mathrm{Sc}$ and $\mathrm{Ti}$, are listed in the Table. This experimental values $\eta_{\mathrm{KL}}$ are compared with the theoretical values calculated by Rao et al. [16].

Our experimental values were then fitted to a third-order polynomial as a function of atomic number $\mathrm{Z}$ $\left(\Sigma A_{n} Z^{n}\right)$ and fitted values of the $\mathrm{K}$ to $\mathrm{L}$ shell vacancy transfer probability listed in the Table. These values are plotted as a function of the atomic number in Fig. 2. Fitted coefficients are also presented in Fig. 2. Using these fitted values, the required experimental $\mathrm{K}$ to $\mathrm{L}$ shell vacancy transfer probability for individual elements can be obtained for comparison and the fit will be valid in the atomic range $16 \leq Z \leq 22$.

The experimental results alongside with the theoretically calculated values and semiempirical values are represented graphically as vacancy transfer probabilities versus atomic numbers in Fig. 2. In the theoretically calculated values, the radiative transition rates were taken from [28] and the radiationless (Auger) transition rates were taken from [29].

In this study, the overall uncertainties in the present measurements is estimated to be less than $5-8 \%$. This is attributed to the uncertainties in different parameters used to deduce $\eta_{\mathrm{KL}}$ values; namely, that in the area evaluation under the $\mathrm{K}_{\alpha}$ and $\mathrm{K}_{\beta}$ X-ray peak $(<3 \%)$, in the absorption correction factor ratio $(<2 \%)$, the product $\mathrm{I}_{0} \mathrm{G} \varepsilon(3 \%)$ and the other contributions $(<2 \%)$. 


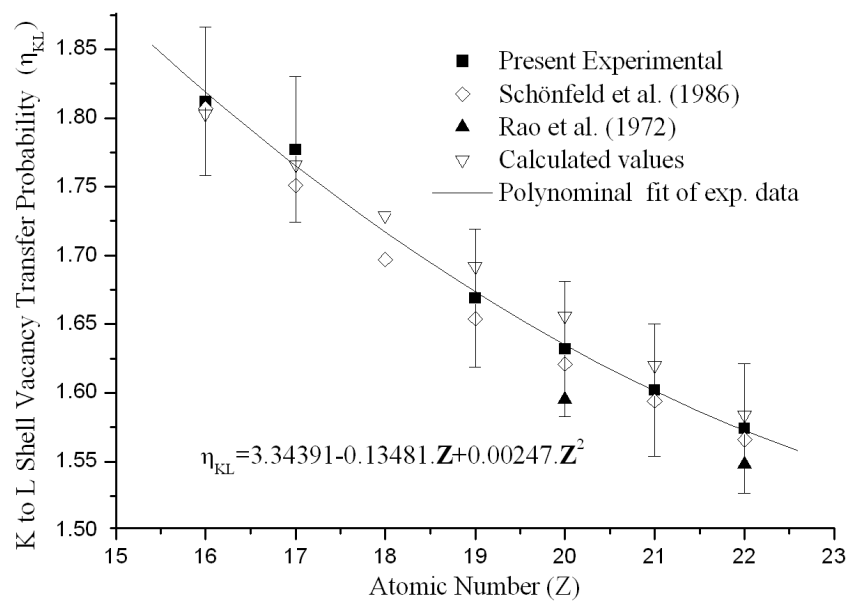

Fig. 2. $\quad \eta_{\mathrm{KL}}$ as a function of atomic number $Z$.

It can be seen from the Table and Fig. 2, that our measured values are in good agreement, within the experimental uncertainties, with the calculated theoretical values for the elements $16 \leq Z \leq 22$. The experimental values are generally lower than theoretical results. One of the reasons for this may be chemical effect that occurred because of their compound structure. As one would expect that besides the $\mathrm{K}$ X-rays and the secondary electrons from the high $\mathrm{Z}$ element can enhance the K X-ray yields of the low Z elements, more photons and electrons such as the Compton electrons and the Compton scattering photons may be energetically possible to ionize the K-shell electrons of the lower $\mathrm{Z}$ elements but not enough to ionize the higher $\mathrm{Z}$ ones. The agreement between the present results and theoretical predictions are within the range $0.5-1.5 \%$ for the $\mathrm{K}$ to $\mathrm{L}$ shell vacancy transfer probability. As the present measurement was carried out in air, Ar $\mathrm{K}$ lines were observed in almost all of spectra. The $\mathrm{K}$ lines for present elements separated from the Ar K lines and so, for these targets, there was no problem in evaluating the peak integral of the $\mathrm{K}$ X-ray lines.

TABLE

Comparison of experimental and theoretical results for K to L shell vacancy transfer probabilities.

\begin{tabular}{c|c|c|c|c}
\hline \hline \multirow{2}{*}{ Elements } & \multicolumn{3}{|c}{$\eta_{\text {KL }}$} \\
\cline { 2 - 5 } & Present exp. & $\begin{array}{c}\text { Fitted exp. } \\
\text { values }\end{array}$ & $\begin{array}{c}\text { Theoretical } \\
\text { values }\end{array}$ & $\begin{array}{c}\text { Other theoretical values } \\
\text { Ref. [16] }\end{array}$ \\
\hline${ }^{16} \mathrm{~S}$ & $1.812 \pm 0.054$ & 1.819 & 1.803 & - \\
${ }^{17} \mathrm{Cl}$ & $1.777 \pm 0.053$ & 1.765 & 1.766 & - \\
${ }^{18} \mathrm{Ar}$ & - & 1.717 & 1.729 & - \\
${ }^{19} \mathrm{~K}$ & $1.669 \pm 0.050$ & 1.674 & 1.692 & 1.595 \\
${ }^{20} \mathrm{Ca}$ & $1.632 \pm 0.049$ & 1.635 & 1.656 & - \\
${ }^{21} \mathrm{Sc}$ & $1.602 \pm 0.048$ & 1.602 & 1.620 & 1.548 \\
${ }^{22} \mathrm{Ti}$ & $1.574 \pm 0.047$ & 1.573 & 1.584 &
\end{tabular}

According to earlier methods [3-14], it is necessary to measure L X-ray production cross-sections at above and below energies from $\mathrm{K}$ shell binding energy. For the $\mathrm{Si}(\mathrm{Li})$ or $\mathrm{Ge}(\mathrm{Li})$ spectrometer, it is not possible to determine L X-ray line intensities for the low atomic number elements because of detector efficiency. Present method allowed us to measure $\mathrm{K}$ to $\mathrm{L}$ shell vacancy transfer probabilities for low atomic number elements, since we can measure K X-ray intensity for these elements using a $\mathrm{Si}(\mathrm{Li})$ detector.

Due to the absence of experimental data in the literature, our experimental values could not be compared with the other experimental values.
In conclusion, the present good agreement with the theoretical values leads to the conclusion that the present method will be beneficial for determining of vacancy transfer probability in the low atomic number and satisfactory for many other applications employing the fundamental parameter approach.

\section{References}

[1] B. Ertuğral, U. Çevik, E. Tırasoğlu, A.I. Kobya, M. Ertuğrul, O. Doğan, J. Quant. Spectrosc. Radiat. Transfer 78, 163 (2003).

[2] O. Doğan, Ö. Şimsek, Ü. Turgut, M. Ertuğrul, J. Rad. Nucl. Chem. 232, 143 (1998).

[3] M. Ertuğrul, Spectrochim. Acta Part B 52, 201 (1997). 
[4] Y. Özdemir, R. Durak, E. Öz, Radiat. Phys. Chem. 65, 199 (2002).

[5] M. Ertuğrul, Nucl. Instrum. Meth. B 124, 475 (1997).

[6] E. Trraţoğlu, U. Çevik, B. Ertuğral, Y. Atalay, A.Ý. Kobya, Radiat. Phys. Chem. 60, 11 (2001).

[7] S. Puri, D. Mehta, N. Singh, P.C. Mangal, P.N. Trehan, Nucl. Instrum. Meth. B 49, 319 (1993).

[8] G. Apaydın, E. Tıratoğlu, U. Cevik, B. Ertuğral, H. Baltaş, M. Ertuğrul, A.Ý. Kobya, Radiat. Phys. Chem. 72, 549 (2005).

[9] M. Ertuğrul, Appl. Radiat. Isot. 57, 63 (2002).

[10] M. Ertuğrul, J. Quant. Spectrosc. Radiat. Transfer 72, 567 (2002).

[11] E. Tı raţoğlu, U. Çevik, B. Ertuğral, G. Apaydın, M. Ertuğrul, A.Ý. Kobya, Eur. Phys. J. D. 26, 231 (2003).

[12] S. Puri, D. Mehta, B. Chand, S. Nirmal, P.N. Trehan, Nucl. Instrum. Meth. B 73, 443 (1993).

[13] S. Puri, D. Metha, B. Chand, N. Singh, J.H. Hubbell, P.N. Trehan, Nucl. Instrum. Meth. B 83, 21 (1993).

[14] B. Ertuğral, G. Apaydın, H. Baltaş, U. Cevik, A.Ý. Kobya, M. Ertuğrul, Spectrochim. Acta. Part B 60, $519(2005)$

[15] B. Ertuğral, G. Apaydın, A. Tekbıyık, E. Tirasoğlu, U. Cevik, A.I. Kobya, M. Ertuğrul, Eur. Phys. J. D 37, 371 (2006)

[16] V.P. Rao, M.H. Chen, B. Crasemann, Phys. Rev. A 5, 997 (1972).
[17] E. Schönfeld, H. Janßen, Nucl. Instrum. Meth. A 369, 527 (1996)

[18] S. Puri, D. Mehta, B. Chand, N. Singh, P.N. Trehan, Nucl. Inst. Meth. B 74, 347 (1993).

[19] M. Ertuğrul, O. Doğan, Ö. Şimşek, Ü. Turgut, Phys. Rev. A 55, 303 (1997).

[20] M. Ertuğrul, Spectrochim. Acta. Part B 57, 63 (2002).

[21] M. Ertuğrul, J. Anal. At. Spectrom 17, 64 (2002).

[22] M. Ertuğrul, J. Phys. B, At. Mol. Opt. Phys. 36, 2275 (2003)

[23] W. Bambynek, in: Proc. X-ray and Inner-Shell Processes in Atoms, Molecules and Solids, Ed. A. Meisel, Atomic Data, Leipzig 1984

[24] M.J. Berger, J.B. Hubbell, S.M. Seltzer, J.S. Coursey, D.S. Zucker, NIYST Standart Reference Database 8 (XGAM), (1998).

[25] E. Storm, I.H. Israel, Nucl. Data Tables A 7, 565 (1970).

[26] J.H. Scofield, Lawrence Livermore Laboratory Report, UCRL-51326 (1973)

[27] N. Broll, X-ray Spectrom 15, 271 (1986).

[28] J.H. Scofield, Atom. Data Tables 14, 121 (1974).

[29] M.H. Chen, B. Crasemann, H. Mark, At. Data Nucl. Data Tables 24, 1337 (1979). 